\title{
APÉNDICE: \\ POR LA REFUNDACIÓN DEL SISTEMA DE EDUCACIÓN ${ }^{32}$
}

\author{
Manuel Antonio Garretón Merino
}

32 Este artículo profundiza y detalla los argumentos presentados por el autor en el coloquio "Reforma y Educación Pública: Reflexión y debate desde la Universidad de Chile". 


\section{MANUEL ANTONIO GARRETÓN}

Sociólogo de la Pontifica Universidad Católica de Chile. Doctorado en l'Ecole des Hautes Etudes en Sciences Sociales, Paris. Premio Nacional de Humanidades y Ciencias Sociales y Profesor titular de la Universidad de Chile. 


\section{POR LA REFUNDACIÓN DEL SISTEMA DE EDUCACIÓN}

Partamos recordando que todo modelo educacional es expresión de un modelo social y de una visión o proyecto de sociedad, aunque ello no sea una relación mecánica y juegue en ambos sentidos. Lo fue en el caso chileno, durante el siglo veinte hasta 1973. Los cambios en la esfera educacional pretendían adaptar el sistema a las transformaciones de la sociedad, la que buscaba industrializarse, modernizarse y profundizar socialmente su democracia en el marco de ese régimen político. La década del sesenta, con sus movimientos de reforma y sus políticas estatales, ilustran estos cambios tanto en el sistema escolar como en la educación superior, creándose ocho universidades por ley, conocidas hoy como las universidades tradicionales.

A partir de la instalación de la dictadura militar, las relaciones entre modelo educacional y orden económico social se hicieron más estrechas en la medida en que el nuevo orden socio-económico impuesto, desde el tratamiento de shock de 1975 y recompuesto a partir de 1986 después del gran fracaso de 1981/82, implicó que, con toda la fuerza de la represión, se buscara desarticular desde el comienzo lo que había sido el sistema educacional hasta entonces. También que a partir de 1979 (Directivas Presidenciales) en el ámbito escolar, y de 1981 (decretos sobre las universidades) en la educación superior, se buscara fundar un nuevo modelo basado en principios y estructuras radicalmente contradictorios a lo que habían sido hasta entonces.

En efecto, lo que hace la dictadura militar en el plano educacional es revertir las grandes tendencias del sistema educacional chileno: educación básicamente pública o estatal y gratuita en todos los niveles, con un espacio acotado para la educación privada, pero siempre con hegemonía de la educación pública con creciente democratización y ampliación de sus acceso, pese a lo aún limitado de la cobertura, y de calidad adecuada a la época. Se crea un sistema que busca explícitamente desarticular y reducir la educación pública, trasladando a las municipalidades sin recursos el papel del Estado en el sistema escolar, otorgándole al mercado el rol de mecanismo principal en la asignación de los servicios educacionales, y al sector privado el papel mayoritario y hegemónico, esto último en todos los niveles del sistema. En el ámbito de la educación superior este viraje se hace a través de la desarticulación de las universidades estatales y la introducción del principio de autofinanciamiento, y la generación de un gran número de instituciones privadas sin mayor regulación. Después de un período de baja de la cobertura durante el 
régimen militar, la expansión de ésta en todos los niveles se hizo a costa de la educación estatal y pública y del endeudamiento de las familias. El principio de subsidiariedad del Estado en el sistema educacional, la introducción del lucro en el sistema escolar privado con financiamiento público y el nuevo sistema universitario privado creado (aunque la ley teóricamente no lo permitía), así como el principio del autofinanciamiento en las instituciones públicas de educación superior, la selección, etc., generaron un modelo caracterizado por la segmentación y la desregulación en todos los niveles. Produjeron también la ausencia del Estado en los niveles técnicoprofesionales de la educación superior y el debilitamiento de las Universidades estatales. Sus objetivos y resultados, como lo ha señalado la OECD, lo convirtieron en uno de los sistemas más segregados, desiguales, caros y con menor participación del Estado en todo el mundo.

Esta fue la herencia que recibió la democracia chilena y los gobiernos que la inauguraron sucediendo a la dictadura. Por supuesto que tal sistema educacional estaba íntimamente asociado al proyecto de sociedad que implantó la dictadura militar, basado en la visión ideológica de sus sectores civiles de apoyo, especialmente los llamados gremialistas y Chicago Boys. Esto es lo que se ha llamado modelo neoliberal, cuyos rasgos centrales son la predominancia del mercado en todos los ámbitos de la vida social, la reducción del papel del Estado y las consiguientes desigualdades en todas las dimensiones de la vida social y concentración de la riqueza y poder en muy pocas manos. El modelo educacional reproducía y al mismo tiempo producía los rasgos del modelo socioeconómico.

Pero tal asociación era permitida y asegurada por un modelo sociopolítico consagrado en toda la institucionalidad estatal, partiendo por la Constitución de 1980. La transformación estructural del modelo educacional desde uno privado, en su mayoría, hacia un sistema público y gratuito, se hacía prácticamente imposible en el sistema institucional heredado de la dictadura. Este sistema institucional, construido en torno al principio de propiedad que carece de legitimidad en su génesis, se expresa en la Constitución Política de 1980, que establece un empate político entre aquellos agentes políticos que están por defender y mantener el actual modelo económico y social de tipo neoliberal (en el cual el mercado se impone como eje central de las relaciones sociales; el sistema educacional consagra el papel subsidiario del Estado; la educación no es un derecho y la libertad de enseñanza equivale a la libertad de empresa; la educación es predominantemente privada y la estatal tiende a disminuir; y en consecuencia, a desaparecer) y aquellos amplios sectores que buscan su transformación hacia otro tipo de modelo donde no sea el mercado el eje central de las relaciones sociales, sino más bien el Estado en tanto motor de desarrollo. 
Todo lo anterior está documentado y fundamentado, por lo que no insistiremos en ello. Pero negar esta realidad y la vinculación entre modelo educacional, modelo socioeconómico y modelo político institucional es desconocer el carácter profundamente fundacional que tuvo en la educación y en la sociedad la dictadura militar y, por lo tanto, evitar la cuestión de la necesaria refundación del modelo educacional si queremos tener una sociedad distinta a la impuesta por dicha dictadura.

De modo que los gobiernos democráticos post transición heredaron un sistema educacional producto de una verdadera revolución o contrarrevolución y se enfrentaron a un dilema no tan diferente del que tuvieron respecto del modelo socioeconómico: corregir sus problemas principales o revertir las transformaciones realizadas por la dictadura e iniciar un proceso de cambio sustantivo del modelo o sistema heredados. La opción de los gobiernos de la Concertación, en la que primaron los temores a los cambios de tipo fundacional por parte de la elite dirigente de la coalición (el concepto de reforma educacional fue excluido y reemplazado por mejoramiento de la calidad y equidad), fue la primera. Ello se tradujo en un importante programa dirigido a mejorar las condiciones del sistema en los sectores más vulnerables, modernizar el curriculum escolar y aumentar la jornada escolar, expandir la cobertura en los niveles medio y pre-escolar, y educación media obligatoria, entre otras medidas. En el sistema universitario la opción explícita fue consolidar el modelo de educación superior, privilegiando ideas como la autorregulación de las instituciones y, más adelante, la acreditación en manos de agencias privadas o el tema del financiamiento del acceso a este nivel a través de un sistema que significó un aumento de cobertura y alto endeudamiento de las familias. Todo ello, pese a avances significativos en algunos aspectos, no tocó lo central del modelo heredado, que en el caso de la educación superior se caracterizaba por su segmentación y fragmentación, deterioro de las instituciones públicas, predominio de los principios de mercado, multiplicación de instituciones de mala calidad en los tres niveles consagrados (Centros de Formación Técnica, Institutos Profesionales, Universidades), inexistencia de regulación o de instituciones estatales en los CFT y los IP, y endeudamiento creciente de quienes accedían a la educación.

Más allá de las críticas que se hacían desde algunos medios educacionales, centros de investigación, académicos y dirigentes estudiantiles, se impuso la visión de reformar o corregir algunos problemas relevantes, con lo cual se profundizó, consolidó y legitimó el modelo heredado desde la dictadura. Es con las movilizaciones de 2006 por parte de los estudiantes secundarios y las de 2001 con la de universitarios, mayoritariamente, aunque también con participación de estudiantes secundarios, que se produce un cuestionamiento radical del sistema educacional, develando su cuestión central: un modelo basado en la privatización 
y el mercado que generaba desigualdad y mala calidad, y reclamando su sustitución por un sistema que reconoce la educación como un derecho basado en la educación pública, provista y regulada por el Estado, de calidad.

Si bien las movilizaciones de 2006 lograron reformar la ley orgánica constitucional, posteriores medidas profundizaron los rasgos del sistema y el núcleo básico de las reivindicaciones del movimiento fue desvirtuado. Ello tuvo importancia en la profundización de las desconfianzas del mundo social respecto de la política, que estarán presentes en las movilizaciones de 2011 y en la raíz del desentendimiento para promover reformas significativas en el sistema. De hecho, en las movilizaciones de 2011 la demanda estudiantil es la sustitución del actual modelo educacional vinculada a una reforma tributaria para proveer los recursos para el cambio de sistema, así como una modificación constitucional capaz de reemplazar el sistema político heredado. Quedaban así planteados los tres pilares de una refundación del modelo socioeconómico, cultural y político que constituirían el núcleo programático de la coalición que llevaría al Gobierno por segunda vez a Michelle Bachelet.

El meollo de la refundación o transformación del sistema educacional es devolverle a la educación pública su carácter predominante tanto en los aspectos normativos como en los relacionados con matrícula y recursos, lo que implica revertir la tendencia instaurada en la dictadura y mantenida y a veces profundizada por los gobiernos democráticos y sus políticas educacionales. Y ello porque la educación pública y el Estado son los únicos que pueden y deben asegurar la calidad e igualdad en la educación, lo que el mercado y la educación privada no pueden garantizar por cuanto sus finalidades son otras. Ello no significa que la educación privada no tenga un espacio de desarrollo, pero su rol es subsidiario, en esta materia, frente al del Estado y no al revés. Si alguien sostiene que la libertad de enseñanza está por encima o al mismo nivel que el derecho a la educación que el Estado está obligado a proveer, debiera entonces afirmar que esta educación debe ser provista sólo por los mismos individuos o grupos y no debiera reclamar que el Estado la subvencione o financie. Reclamar el derecho absoluto de los padres a elegir el colegio que quieran es ilusorio para la gran mayoría de la población y supone una oferta ilimitada de establecimientos educacionales sin ninguna regulación.

La fundamentación de lo afirmado es obvia: si miramos la sociedad no como una suma de individuos o como algo subsidiario, tal como lo ve el individualismo posesivo y cierto tipo de liberalismo, sino como la condición ineludible para el desarrollo de las personas, las funciones principales de la vida en sociedad deben estar a cargo de ésta y no de individuos o grupos de individuos. Y cuando decimos a cargo de la sociedad significa la organización de la sociedad como Estado, por lo que corresponde a éste la responsabilidad principal de proveer y regular estas funciones, 
entre las cuales están la integridad territorial, la seguridad de su población y, sobre todo, la formación de sus hijos e hijas, es decir, la educación.

Este es un debate zanjado en todas partes del mundo menos en Chile, donde sí lo estuvo hasta la dictadura a través de una provisión mixta, sí, pero con predominio normativo, regulador, de recursos y de matrícula por parte de la educación pública. El argumento que se opone a los cambios educacionales afirmando la necesidad de una provisión mixta olvida que lo que hoy existe está lejos del patrón histórico chileno que, reconociendo este carácter, aseguraba la preeminencia de la educación estatal y reconocía un espacio acotado y subsidiario a la educación privada. Que se haya pasado de más de dos tercios de estudiantes en la educación pública en todos los niveles a cerca de un tercio en el lapso de treinta años ilustra lo afirmado. Y de retomar la tendencia de la educación pública predominante en todos los niveles depende que podamos resolver los problemas de calidad e igualdad del sistema educacional. Por supuesto que devolverle a la educación estatal o pública su carácter predominante en todos los niveles, así como su calidad de derecho de las personas en cuanto miembros de una comunidad por encima de su carácter de bien de consumo, no asegura la calidad y equidad, pero es la condición sine qua non para ello. Y este debe ser el horizonte hacia el cual apunten las políticas educativas.

Este cambio de paradigma fundamental no se logra en el corto plazo, pero exige desde ya al menos revertir la tendencia actual, por lo que los recursos del Estado deben concentrarse en la educación pública. Se trata, entonces, al mismo tiempo de reestructurar ésta y de aumentar significativamente su oferta, de desmontar los mecanismos en que se basa el actual sistema de educación. Todo ello debe realizarse de una manera a la vez firme y sin concesiones respecto de este horizonte, pero con la gradualidad y flexibilidad, lo que implica una transformación de mecanismos e instituciones que han sido reproducidos a lo largo de más de una generación y por lo tanto se han internalizado en muchos sectores que se sienten afectados, más por desconocimiento o confusión que por otra cosa, ante cualquier cambio.

Aquí está planteado el mismo dilema que en el plano general del país: la superación de la sociedad heredada de la dictadura o la corrección en algunos ámbitos manteniendo los pilares fundamentales del modelo socioeconómico y político. Porque una reforma significa corregir, alterar, en general en el sentido de mejorar, parcialmente un determinado ámbito o estructura. Refundar es cambiar las bases o principios en que se asienta ese ámbito o estructura y eso no es una acto preciso y limitado como es la reforma, sino un proceso que marca un horizonte distinto, que apunta a un nuevo modelo de relaciones e instituciones sociales de acuerdo a nuevos principios, pero que está hecho de múltiples reformas concatenadas. Una reforma parcial puede mejorar pero no alterar los principios en que se basa un modelo y, por lo tanto, contribuir a su consolidación, es decir, una reforma no es necesariamente 
fundacional, pero una refundación sólo puede hacerse a través de reformas parciales que se hacen en nombre de nuevos principios. Oponer la reforma a la refundación, en el caso chileno, es o negarse a reconocer la existencia del modelo heredado de la dictadura o aceptarlo como bueno y evitar su cambio. Negar el carácter reformista de una refundación es desconocer el carácter de proceso institucional que una refundación hecha en un marco democrático debe tener.

Es claro que no estamos entonces ante un problema técnico o de expertos en educación, especialmente si se trata de los tecnócratas que sólo manejan indicadores y mediciones socio-económicas y educacionales sin saber nada de educación, sino ante una cuestión ideológica y política que atraviesa a todos, tanto a quienes se oponen a cualquier cambio, como a los reformistas, como a los fundacionales. Cuando se trata de discutir la refundación, a favor o en contra, de un sistema, las grandes opciones son siempre valóricas y quienes esgrimen argumentos técnicos o se refugian en la autoridad de expertos para argumentar en uno u otro sentido, lo que hacen es ocultar dichas posiciones. En todo caso, el grueso de los estudios y la experiencia mundial son claros en asociar la calidad y la equidad o igualdad de la educación con su carácter público, de preeminencia de la provisión estatal, gratuidad y ausencia de lucro, siendo el caso chileno, como hemos indicado, el único que se aparta de estos principios y, por lo tanto, el más segregado, caro y con menor responsabilidad del Estado. Y la cuestión de la calidad tampoco puede plantearse a través de mediciones de determinado tipo de aptitudes y conocimientos, como se hace en nuestro país. Si se trata de formar personas y ciudadanos que participen del destino común de una sociedad en el marco de los rasgos contemporáneos del conocimiento, su calidad sólo puede ser asegurada por una educación hegemónicamente pública. Por supuesto que definidos los principios aparece el componente técnico, pero principalmente el educacional y no el de los que sólo manejan cifras comparativas.

En el nivel escolar, el principio refundacional indicado, predominio de la educación pública, significa al menos la expansión de la oferta pública en todos los niveles y ofrecida a todos los niños y niñas desde el primer momento de su infancia, lo que significa una transformación de la institucionalidad de la educación parvularia; la generación de una nueva institucionalidad pública en el sistema escolar que sustituya a la municipalización; el término de la selección, el lucro y el copago hoy permitidos; el fortalecimiento de la formación y la carrera docente con la restructuración de las carreras pedagógicas.

En la educación superior cabe, por lo menos, redefinir cuáles serán sus niveles y, si se mantienen los actuales, eliminar el lucro en los CFT e Institutos Profesionales, asegurar la presencia principal del Estado en ambos y de éstos en las regiones, con un sistema flexible de relación con las universidades. Respecto de éstas, cabe 
revisar el estatus de una gran parte de las actuales universidades privadas para definir si cumplen con los estándares mínimos de gratuidad, calidad, pluralismo y participación de la comunidad académica en sus gobiernos. En el caso de que los cumplan deberían ser creadas por ley, como las tradicionales. En el caso de que no, podrían constituir otro nivel, tipo college, otorgando un grado inferior al de licenciatura. El Estado debiera concentrar todo sus recursos de becas, subvenciones y aportes basales exclusivamente en las universidades públicas, con aportes específicos sólo por proyectos de interés nacional a las universidades privadas y siempre que no haya capacidad en las estatales para realizarlos. Las universidades estatales debieran realizar un serio esfuerzo por mejorar su calidad y la coordinación entre ellas, con el fin de favorecer especialmente a las regionales. En este nivel, debiera ser el grueso de la oferta de matrículas lo que llevara a la creación de nuevas universidades y a buscar formas de universidades vespertinas de alta calidad. El sistema de acreditación debiera cambiar radicalmente: no puede ser igual para las universidades privadas y públicas, sus plazos deben ser más largos y no puede constituir un drenaje de los recursos universitarios tan grande como el que ocurre actualmente.

Es evidente que todos estos planteamientos no abordan otra cuestión de fondo en cualquier proyecto fundacional que se refiere al sentido y misión de la tarea educacional en el mundo de hoy. La crisis del concepto de escuela y de una educación que ha dejado de ser canal de socialización en muchas partes y que está atravesada por el desafío de las nuevas formas comunicacionales y de convivencia, obliga a un debate largo y profundo y a ir innovando en los estilos y mecanismos educativos y la relación de la escuela con su entorno y con la sociedad. En el caso de las universidades, ello es aún más necesario y urgente, porque, a mi juicio, ellas han seguido en general un camino equivocado para tratar de responder a los desafíos de la sociedad contemporánea y sus grandes transformaciones culturales, al intentar adecuarse a ellos no redefiniendo el sentido de su misión, sino simplemente buscando adaptarse a través de estandarizaciones del quehacer universitario y de mediciones cuantitativas y formales que son simplemente adopciones de modelos externos.

Pero discutir todo esto no puede ser pretexto para postergar indefinidamente las reformas institucionales a que nos hemos referido, como quisieran algunos, porque ello no puede hacerse al margen de tales reformas.

A mi juicio, la Universidad de Chile, más allá de reivindicar aportes y tratamientos del Estado, como la principal universidad pública del país debe liderar con pensamiento, proyecto y propuestas este debate refundacional no sólo de la educación superior, sino del conjunto del sistema educacional. 